\title{
Application and Exploration of Blended Learning Model in College Chinese Teaching
}

\author{
Guodong Xue \\ College of Liberal Arts, Yulin University, Yulin, Shaanxi, China \\ 317950860@qq.com
}

\begin{abstract}
Keywords: College Chinese; Course Design; Blended Learning Mode; Flipped Classroom
\end{abstract}
\begin{abstract}
This paper analyzes the problems existing in the current teaching of the College Chinese, and then the blended learning theory were analyzed. Finally, many methods of hybrid learning theory, such as network teaching system, flipped classroom, MOOC and so on, were applied to the teaching process of the College Chinese, and the teaching effect was analyzed. The teaching practice of three years shows that the blended learning model is beneficial to the teaching of College Chinese, and the students' native language level has been significantly improved.
\end{abstract}

\section{Introduction}

Cyber source based learning is based on computer network and multimedia technology and modern teaching equipment on the combination of the computer network as a carrier of teaching information transmission, so that learners from passive recipients of knowledge into active construction, so as to optimize the structure of courses, improve the teaching effect of a new means of education. As a course of cultural quality education in Colleges and universities, College Chinese has been incorporated into the undergraduate curriculum system, which has been paid more attention than ever before, but the teaching effect is not satisfactory. Therefore, this paper will be closely combined with the teaching practice of "College Chinese" curriculum, and draw lessons from constructivism, cooperative learning and autonomous learning theory on constructing teaching platform of "College Chinese" network course[1-3].

Theoretically speaking, "Mu class" has the applicability to the reform of College Chinese teaching mode. First of all, the College Chinese teaching is still more use of teaching method, but this method of teaching is not attractive to 90 college students. Teachers usually in accordance with the author, writing background, text interpretation, analysis of the characteristics of the students to pass the message to the class, is the speaker of the class; students to passive acceptance, enthusiasm, initiative to play a limited. "Mu" based on the information environment, dapper video as the main learning resources, more suitable for the tastes of students. Secondly, College Chinese is a basic compulsory course, many colleges and universities are in the form of class teaching. A class, less than three or four people, more than a hundred people, the teacher is difficult to achieve the students as the center, the teaching effect is not ideal. In the course of "Mu", the students' autonomous learning is not limited by time and place. Finally, although the Chinese language courses in the university after class thinking, but often a mere formality, the students are really willing to explore after class[4-6].

\section{Current Situation of College Chinese Teaching}

College Chinese is the basic subject in college teaching, most universities college Chinese as a public course or elective courses, the teaching content for a general appreciation of classical literary works, focusing on students' thoughts, emotional education, personality cultivation, cultivate students' learning to cultivate students' writing[7]. However, the present situation of College Chinese teaching is still showing some problems, some colleges and universities do not pay enough attention to the teaching of College Chinese, and students do not pay attention to it. First of all, in the classroom of College Chinese, students to the ground rate is relatively low, the classroom 
performance of the form of a teacher to sing the main character, the classroom atmosphere is boring. The second is the College Chinese teaching methods, most college Chinese teaching is also in accordance with the Chinese teaching method in high school, the article explain the meaning and mixing section are still using the subsection Yu discretionary sentence etc., lack of innovation, the concept of some Chinese teachers is relatively old and does not take into account the characteristics of the times of Chinese university students, so on College Chinese learning is tired of the state. [8,9] With the college students' employment pressure and survival pressure increasing, in order to seek a space for one person in the talent competition, college students have to strive for their proficiency in a particular line mainly in the curriculum, practical choice, for the mother tongue curriculum not interested in. Many students think they have learned more than a decade of Chinese, but also can not speak Chinese, can not write Chinese characters. It is generally believed that the study of Chinese has no substantial help to their employment, and the College Chinese is the "four" language. The Chinese language is equivalent to the middle school language, learning enthusiasm is greatly reduced. College Chinese courses have become a "liberal arts students despise science, science students do not love learning" a course. [10]

\section{Methods and Materials}

At present, the mixed learning is mainly based on the information technology, which is in line with the current trend of the development of the times and the main trend of social development. This paper mainly uses the following methods:

Network Teaching System. Network teaching system is a comprehensive teaching service support system. Based on network media and information technology, teachers can achieve the teaching, coaching, communication and students self-study, homework, testing and quality evaluation and other services, at the same time, it can provide real-time tutoring service for the students.

Flipped Class Model. Flipped classroom is generally referred to as "reverse classroom teaching mode"". In traditional teaching, teachers are the master of learning process. The teacher is responsible for the classroom instruction, the arrangement homework, the usual and the final examination, the revision work and the examination paper and so on, the student coordinates the teacher to carry on the teaching activity. In the teaching process, it is difficult for the teachers to be individualized and diversified teaching. In the flipped classroom, the students become the master of teaching, teachers help students to complete the task of teaching. Students first preview the contents of the class before class, in class for their own difficult problems in the preview, there are key questions, to solve their own problems in a timely manner, to obtain more targeted knowledge. Under the class for not understand the problem, do some homework, master more accurate knowledge. Therefore, in the flipped classroom, the classroom has become a "lovely" space for students to explore the exchange, teachers become students to solve the problem of an auxiliary role. Here, students use the Internet to use quality educational resources, not just rely on the teacher to teach knowledge. The role of teachers in teaching has changed, he is mainly to understand and solve the problems of students, to guide students to learn the right direction, the management of learning process, the organization of cooperative learning. Flip the classroom to make full use of rich information resources, so that students gradually become the protagonist of learning. Therefore, to improve the evaluation mechanism, promote the balanced development of education, while promoting the flip classroom more popular.

\section{Summary}

"Teaching platform" network curriculum of College Chinese teaching function and integrate teaching resources, network teaching resources integration and services for "College Chinese" curriculum provides a useful exploration and attempt. "" the network curriculum of College Chinese teaching platform integration features of many media, making the teaching information can be presented in a variety of ways, teaching content, teaching means more plentiful, more flexible, more 
diverse teaching ways. The model of flexible learning, easy to communicate, can not only realize the cyber source sharing, but also has the characteristics of timeliness, especially students can analyze the changes of the current instant language life in the use of theoretical knowledge learned in the classroom, and a new method for the communication between teachers and students learning, which can be fully exchange and discussion among participants, respecting the individual differences of learners, to broaden their horizons of knowledge, broaden the knowledge structure will be of great advantage.

\section{Acknowledgements}

This paper is a report of the research project of teaching reform in Yulin University.

\section{References}

[1] Y.P.Zhong, Y.J.Guo, X.Y.Luo. Application of Problem-Based Learning mode in nursing practice student teaching. 2015 7th International Conference on Information Technology in Medicine and Education (ITME). 2015

[2] T.Wiktorski, T.Hacker, R.A.Hansen, G.Rodgers. Experience with Problem-Based Learning in a hybrid classroom. 2015 IEEE 7th International Conference on Cloud Computing Technology and Science . 2015

[3] Y.P.Huang. Exploration on the construction of digital signal processing high-quality curriculum. Education and Vocation . 2014

[4] Li ke-dong, Zhao Jian-hua. General Theory and Application Model of Blended Learning. E-education Research . 2004

[5] Z.J.Li. The Research on Course Reform of "Modern Education Technology". China Educational Technology . 2009

[6] Wang Fuyin, Zhang Baorong. A new exploration of the quality of higher education in China: an analysis of the mode of running a school in The University of Nottingham Ningbo [J]. China higher education, 2014 (3)

[7] Yang, Xu Nan, Wang small. The mother tongue education to strengthen college: a survey of more than ten universities at home and abroad based on the analysis of [N]. 2011- 01- 11 Guangming Daily.

[8] Peng. College Chinese should become an independent subject [N]. Chinese Social Science Journal, 2014- 7- 21 Liu Xiuling, Guo Xiaolu

[9] Implementation strategy of applied talents training in College Chinese course of non liberal arts [J]. Journal of Yangzhou University, 2014 (4)

[10]Zhou Jinsheng, Zhang Xiangping. The essence of the Chinese language and the way to reform [J]. education review, 2014 (7) 